\title{
A política de desenvolvimento sustentável da Vale
}

RESUMO: Este trabalho, a partir de um ponto de vista crítico, identificado com a ecologia política, visa contribuir para o estudo da temática dos conflitos socioambientais considerando a necessidade de se compreender a atuação de determinados agentes particulares que interferem no campo sócio-econômico e político-ambiental. Como objeto de estudo, selecionou-se a Companhia Vale do Rio Doce (CVRD), atualmente Vale S.A, por sua ação em mais de 30 países que tem gerado vários impactos socioambientais. Assim, analisamos o documento intitulado "Política de Desenvolvimento Sustentável", decompondo os elementos que a constituem e buscando, quando possível, redarguir as afirmações presentes no documento com casos concretos.

\section{Valley's sustainable development policy}

\begin{abstract}
This work, from a critical point of view, identified with political ecology, aims to contribute to the theme of environmental conflicts considering the necessity to understand the actions of certain particular agents that interfere in the socio-economic and political-environment fields. As the object of this study, were selected the Valley of the Rio Doce Company (CVRD), currently Valley SA, for its action in over 30 countries which has caused many environmental impacts. Thus, we analyzed the document entitled "Sustainable Development Policy", decomposing the elements that constitute it and seeking, when it is possible, to reprove the present affirmations in the document with concrete cases.
\end{abstract}

José Arnaldo Ribeiro Junior* Horácio Antunes Sant'Ana Júnior**

*Membro do Grupo de Estudos Desenvolvimento, Modernidade e Meio Ambiente (GEDMMA) e do Núcleo de Estudos e Pesquisa do Sindicalismo (NEPS).

${ }^{* *}$ Professor Adjunto do Departamento de Sociologia e Antropologia da Universidade Federal do Maranhão, Vice-Coordenador do Programa de Pós-Graduação em Ciências Sociais; Professor do Programa de PósGraduação Políticas Públicas da mesma instituição.

Palavras-chave: Vale; Política ecológica; Desenvolvimento sustentável; Mineração e siderurgia; Conflitos ambientais.

Key-words:

Valley; Political Ecology; Sustainable development; Mining and steel; Environmental conflicts.. 
Desde 2007, a Companhia Vale do Rio Doce utiliza o termo Vale como nome fantasia.

2 Cabe destacar que é dessa forma que se estrutura 0 Sistema Norte da Vale: um complexo mina-ferrovia-porto, ou seja, província mineral de Carajás, (PA) - Estrada de Ferro Carajás (EFC) - Terminal Portuário Ponta da Madeira (São Luís - MA).

\section{Considerações iniciais: objetivo e princípio da política de desenvolvimento sustentável}

Uma das maiores mineradoras do mundo, a Vale ${ }^{1}$ qualifica-se como uma empresa que transforma recursos minerais em utensílios necessários para o cotidiano das pessoas. Reflexo da internacionalização do capital, ela é uma empresa multinacional sediada no Brasil que conta com mais de 100 mil empregados, entre terceirizados e próprios. Desde 1976, ano em que 0 decreto $n^{0} 77.608$ outorgou a Vale a concessão para a construção, uso e exploração da Estrada de Ferro entre Carajás (PA) e a capital do Maranhão (São Luís), a Vale tem atuado diretamente e indiretamente no espaço maranhense, fato esse que tem contribuído decisivamente para a promoção de impactos socioambientais (desde poluição atmosférica até deslocamento de populações). Em 1986, a Vale inicia as operações no Terminal Portuário de Ponta da Madeira como forma de auferir lucros e vantagens com o escoamento de sua produção de minério de ferro, principalmente ${ }^{2}$. Este fator configura uma vantagem geográfica quando da tentativa de instalação do pólo siderúrgico em São Luís, no ano de 2001, numa ação empreendida pelo Governo Federal, o Governo Estadual do Maranhão e a prefeitura de São Luís, haja vista as condições portuárias de São Luís eram extremamente benéficas ao empreendimento (AQUINO, SANT'ANA JÚNIOR, 2009). Esse pequeno histórico da Vale em território maranhense, e principalmente ludovicense, nos permite compreender a importância da cidade de São Luís para a Vale (p. ex. escoamento da produção), no seio do Programa Grande Carajás, bem como a importância da Vale para o crescimento econômico do Maranhão que, como bem mostrou Holanda (2008, p.15) adveio "da indústria extrativa mineral (15,9\% a.a.) e da construção civil (14,6\% a.a.), refletindo a forte concentração de investimentos públicos e privados". No entanto, a verdade é que quando um projeto de desenvolvimento (indústrias principalmente) se instala em um determinado lugar profundas mudanças estruturais são processadas, tais como: mudanças na articulação e apropriação do território, reorganização da economia e crescimento urbano desordenado.

Ao longo deste trabalho será promovida uma análise do documento intitulado: "Política de Desenvolvimento Sustentável", que está acessível no site www.vale.com. O documento é composto inicialmente pelos itens Objetivo e Princípio, que, então, é decomposto em três partes intituladas: OPERADOR SUSTENTÁVEL; CATALISADOR DO DESENVOLVIMENTO LOCAL; AGENTE GLOBAL DE SUSTENTABILIDADE e que cada parte desta é apresentada na forma de acróstico, construídos respectivamente, a partir dos termos VALOR, LOCAL e GLOBAL. Vejamos então, qual é o Objetivo da referida política da Vale.

Estabelecer diretrizes e princípios para a nossa atuação quanto ao Desenvolvimento Sustentável de nossos projetos e operações, explicitando a nossa responsabilidade social, econômica e ambiental nas regiões em que estamos presentes, em nossa cadeia de valor e no posicionamento sobre temas globais de sustentabilidade (VALE, 2009a, p. 1).

A sustentabilidade global é temática presente nos documentos oficiais da Vale. Não só por ela ser uma empresa global, bem como a sustentabilidade acabou se configurando como mais um vetor de geração de lucro e agregação de valor nas mais diferentes localidades. Dessa forma, a própria responsabilidade socioambiental transforma-se em mais um mecanismo político para que as operações e projetos vinculados à referida empresa estejam imersos no discurso do desenvolvimento sustentável (RIBEIRO JUNIOR; SANT'ANA JÚNIOR, 2010). É pertinente, então, observar que o desenvolvimento sustentável foi conceituado na Comissão 
Mundial para o Meio Ambiente e Desenvolvimento, das Nações Unidas, precisamente em 1987, através do Relatório "Nosso futuro comum", redigido sob a coordenação da ex Primeira Ministra da Noruega, Gro Bundtland. Nesse documento, desenvolvimento sustentável é definido como "aquele que atende às necessidades presentes sem comprometer a possibilidade de as gerações futuras satisfazerem suas próprias necessidades" (CMMAD, 1991, p.46) $)^{3}$. Dito isso, vejamos um caso concreto de atuação da Vale: $O$ município de Barcarena-PA, que sedia as plantas industriais, integra o conhecido Programa Grande Carajás (PGC) e está inserido na cadeia produtiva de Alumina e Alumínio, através das subsidiarias Albrás e a Alunorte. Graças ao insumo da energia elétrica, a Albrás e a Alunorte formam um dos maiores complexos de alumínio a nível mundial.

A ação das subsidiárias da Vale tem gerado impactos relevantes no que tange a emissão de poluentes (gases cáusticos e poeiras corrosivas, bem como a liberação de dióxido e trióxido de enxofre) e aos acidentes ocorridos.

\begin{abstract}
Um dos maiores impactos causados pela produção de alumínio é a lama vermelha, que é a parte estéril do processo de beneficiamento da bauxita. É um resíduo extremamente cáustico, com Ph acima de 13,2. A soda cáustica presente na lama vermelha contribui para a ocorrência de chuva ácida, contamina o lençol freático, as águas superficiais e os solos. Para cada tonelada de alumina produzida, são necessárias três toneladas de bauxita, proveniente de Carajás, o que gera uma enorme quantidade de lama vermelha como resíduo. Somente em 2004 a ALUNORTE produziu, no mínimo, 1,27 milhão de toneladas de lama vermelha. A expansão de sua produção em 2008 aumentou sua capacidade de produção para 2,04 milhões de toneladas de lama vermelha. Apesar da empresa alegar que lança lama vermelha apenas em locais seguros, muitos acidentes têm ocorrido. 0 mais recente ocorreu em abril de 2008, onde milhares de litros de lama vermelha vazaram de uma das bacias daquela empresa, contaminando o rio Murucupi, importante fonte de água para as populações tradicionais (ORGANIZAÇÕES et al, 2010, p. 65, grifos nossos).
\end{abstract}

Talvez não devêssemos nem classificar essa situação descrita acima como um "acidente": isso porque a noção de acidente nos remete a um acontecimento casual, o que não se aplica às operações da Vale. Da mesma forma que seus lucros não são casuais, ou acidentais, mas sim fruto de suas estratégias políticas e econômicas, não se pode classificar como fortuito a contaminação de lama vermelha em ecossistemas fluviais.

Segundo o jornalista Rogério Almeida ${ }^{4}$ A cadeia do alumínio se encontra em franco processo de expansão. A hidrelétrica de Tucuruí teve a sua capacidade produtiva duplicada. Minas no município Paragominas, nordeste do Pará são exploradas, para reforçar a antiga mina em Oriximiná, oeste do estado. Na mesma região, no município de Juruti, a multinacional Alcoa inicia uma conturbada exploração de mina. Há ações dos Ministérios Públicos Estadual e Federal contra a atuação da ALCOA. A Vale pretende ainda a construção de uma usina termoelétrica em Barcarena, orçada em US\$ 898 milhões. Nesse aspecto, a Vale informou que está, por enquanto, suspenso o projeto de construção de uma usina termelétrica no município de Barcarena. O empreendimento teve sua licença prévia expedida pela Secretaria de Meio Ambiente do Estado no final de outubro de $2008^{5}$.

O direcionamento para investimentos em logística tem sido uma sinalização da companhia, em particular na geração de energia. $O$ saque das riquezas e a internalização das tragédias sociais e ambientais têm regido tais projetos de desenvolvimento na Amazônia.
${ }^{3}$ Para uma crítica à noção de desenvolvimento sustentável, ver SANT'ANA JÚNIOR Horácio de Antunes; MUNIZ, Lenir Moraes. Desenvolvimento sustentável: uma discussão crítica sobre a proposta de busca da sustentabilidade global. In: SANT'ANA JÚNIOR, Horácio de Antunes; PEREIRA Madian J. F; ALVES, Elio J. P; PEREIRA, Carla R. A (Org.). Ecos dos conflitos socioambientais: a RESEX de Tauá-Mirim. São Luís: EDUFMA, 2009. p. 255-276.

\section{http://rogerioalmeidafuro.blogsp ot.com/}

${ }^{5}$ www.diariodopara.com.br
Geografia Ensino \& Pesquisa, v. 15, n.3, p. 7-26, set./dez. 2011

Ribeiro Junior, J. A.; Sant'Ana Júnior, H. A. ISSN 2236-4994 
6 Fica a cerca de 100 quilômetros a oeste da cidade de Saint John. Sandy Pond é uma nascente de lago de 38 hectares perto da comunidade de Long Harbour.

7 Pesquisadora coordenadora do Minning Watch Canadá (Observatório da Mineração Canadá).
Já observamos inicialmente que o objetivo da política de desenvolvimento sustentável da Vale é sustentar a sua política de desenvolvimento, nem que para isso os rejeitos de suas operações de mineração destruam ecossistemas naturais. Passemos então agora para 0 Princípio da sua política de desenvolvimento sustentável:

[...] o desenvolvimento sustentável é atingido quando seus negócios, em particular as suas atividades de mineração, geram valor para seus acionistas e demais partes interessadas, e deixam um legado social, econômico e ambiental positivo nos territórios onde opera (VALE, 2009a, p. 1).

Note-se que o desenvolvimento sustentável é um alvo a ser atingido quando seus negócios geram valor para os acionistas. Todavia, a "atuação sustentável" da Vale, a imagem de sucesso que a maioria das pessoas possuem a seu respeito fica manchada quando tomamos notícia de seu desempenho, por exemplo, no Canadá. No referido país a Vale adquiriu a Inco (FIGURA 01) no ano de 2006 com o objetivo de processar níquel.

Figura 01- Campanha da Vale Inco cuja tradução nos diz: "juntos somos melhores". Agora cabe questionar melhor para quem? Um melhor futuro para quem?

Fonte: www.vale.com

Obviamente, qualquer atividade de mineração gera rejeitos que devem ser condicionados adequadamente em um lugar que impacte ou prejudique na menor escala possivel. Aí se encontra o problema: a Vale argumenta "sustentavelmente" que a melhor maneira de se desfazer dos rejeitos da sua refinaria é descartando-o com "responsabilidade social, econômica e ambiental" no lago de Sandy Pond ${ }^{6}$ península Avalon em Newfoundland (Canadá). Nas palavras de Catherine Coumans ${ }^{7}$ :

Canadá não deve prover às indústrias mineradoras subsídios incomensuráveis sacrificando reservatórios de água naturais para se tornarem reservatórios de rejeitos [...] Destruir Sandy Pond não é claramente praticar desenvolvimento sustentável e nem mesmo pode ser considerada uma boa prática em se tratando de reservatórios de rejeitos, uma vez que Vale Inco sabe de antemão que Sandy Pond irá dispersar rejeitos em águas subterrâneas, criando uma pluma contaminante. Além 
disso, a lagoa irá requerer barragens para segurar os rejeitos e essas barragens precisarão ser mantidas para sempre (ORGANIZAÇÕES et al, 2010, p.122).

Seria irônico se não fosse triste. A destruição do lago Sandy Pond, através do lixo tóxico oriundo da refinaria de níquel, ocasionará um desequilíbrio ecológico em um sistema natural que não pode ser substituído, sem falar que trará conseqüências desastrosas para a pesca na região.

\section{Operador sustentável}

Um dos três pilares da Vale é o operador sustentável. "Operar com sustentabilidade é atuar com consciência e responsabilidade socioeconômica e ambiental em todo o ciclo de vida das nossas atividades. É criar "V.A.L.O.R." (VALE, 2009a, p. 1).

Principalmente "V.A.L.O.R. D.E. T.R.O.C.A.", diga-se de passagem. A atividade da Vale é criar valor de troca para seus acionistas, isso sim é operar sustentavelmente, no qual a sustentabilidade é a das ações que operam nas bolsas de valores de São Paulo e Nova York. Vamos então analisar "letra por letra", primeiro o "V", que significa: Valor para stakeholders (partes interessadas).

Proporcionar o maior retorno possível aos acionistas, manter relações e condições justas de trabalho para empregados e contratados, buscar parcerias de longo prazo com fornecedores que tragam ganhos para ambas as partes, garantir maior confiabilidade de suprimento e de valor de uso para nossos clientes, além de contribuir com o desenvolvimento sustentável das comunidades, regiões e países onde operamos, mantendo um relacionamento e diálogo permanente e aberto com nossos stakeholders (VALE, 2009a, p. 1).

As partes interessadas, notadamente, não são as comunidades as quais a Vale agride, ou melhor, atua, mas sim os seus clientes, fornecedores e acionistas que usufruem dos produtos originados, permitindo que a Vale crie valor de troca para ela mesma, possibilitando assim "o maior retorno possível para os acionistas" (RIBEIRO JUNIOR; SANT'ANA JÚNIOR, 2010).

Focalizemos quando a Vale fala em "manter relações e condições justas de trabalho para empregados e contratados": com a compra (por US\$19 bilhões) da Inco, a mineradora canadense, em 2006, a Vale se tornou a maior produtora mundial de níquel. Todavia, o alto custo da operação aumentou o endividamento da Vale para US\$ 22 bilhões em 2006 (Godeiro et.al.2007).

A Vale quer fazer com que as pessoas creiam que o problema é o custo do trabalho, ao invés dos preços de commodities abaixo do esperado, combinados com o custo de aquisição da Inco (que ela não deveria ter pago). A Vale quer manipular uma situação econômica temporária para impor a filosofia de que as empresas têm apenas um dever limitado de compartilhar de forma expressiva seus ganhos com os trabalhadores, e de que não têm responsabilidades de longo prazo para com os trabalhadores e suas comunidades.

As exigências da Vale incluem: uma redução no abono vinculado ao preço do níquel; a eliminação do plano de pensão tradicional (com benefícios definidos) para novos funcionários; e uma redução dos direitos dos trabalhadores no local de trabalho quanto ao agendamento e a alocação

Geografia Ensino \& Pesquisa, v. 15, n.3, p. 7-26, set./dez. 2011

Ribeiro Junior, J. A.; Sant'Ana Júnior, H. A.

ISSN 2236- 4994 
de tarefas. Ao mesmo tempo, a Vale tem falado em reduzir ainda mais o número de empregos e já começou a implantar um sistema global de compras de insumos, cortando, assim, seus laços com muitas empresas locais de serviços de mineração (ORGANIZAÇÕES et al, 2010, pp.104105, grifos nossos).

Como se observa, a diretoria da Vale distorce o conceito de justiça. A única justiça que a Vale concebe é castigar os trabalhadores em virtude da crise econômica. 0 exclusivo retorno que a empresa "cada vez mais verde e amarela" dá aos seus trabalhadores canadenses é uma política agressiva que objetiva romper direitos trabalhistas. As parcerias de longo prazo dissolveram-se em um momento de crise econômica e agora a empresa quer os trabalhadores e as comunidades do Canadá paguem por essa crise. Não obstante, os ganhos são para seus acionistas e o prejuízo afeta trabalhadores e comunidades. Passemos para letra $A$, que significa: Antecipação e prevenção de falhas.

\begin{abstract}
Atuar preventivamente, visando evitar falhas de processo, poluição ambiental, acidentes de trabalho, riscos ocupacionais à saúde, e minimizar impactos sociais e ambientais negativos. Aplicar em todos os projetos de investimento e operações da empresa uma análise prévia de gestão de riscos, impactos e oportunidades nos aspectos ambiental, social e econômico. Investir e utilizar tecnologias que permitam - a custo compatível - maximizar a eco-eficiência, a segurança e a sustentabilidade dos processos produtivos, produtos comercializados e modais de transporte (VALE, 2009a, p. 1, os grifos são meus).
\end{abstract}

O que a Vale chama de impactos sociais e ambientais negativos, que ela julga querer minimizar, são os danos provocados por suas siderurgias e pela atividade mineradora, que acaba por deflagrar conflitos ambientais nos locais onde a referida empresa se instala. Note-se que, na citação acima, a Vale também aborda e reduz a problemática ambiental a um simples problema tecnológico (MARTíNEZ ALIER, 2007). É interessante perceber que a Vale aponta também que estas tecnologias, têm como função maximizar a eco-eficiência. Mas o que é essa eco-eficiência? Segundo Martínez Alier (2007, pp.26-27, os grifos são nossos):

Sua atenção está direcionada para os impactos ambientais ou riscos à saúde decorrentes das atividades industriais, da urbanização e também da agricultura moderna. [...] se preocupa com a economia em sua totalidade. Muitas vezes defende o crescimento econômico, ainda que não a qualquer custo. Acredita no "desenvolvimento sustentável", na "modernização ecológica" e na "boa utilização" dos recursos. Preocupa-se com os impactos da produção de bens e com o manejo sustentável dos recursos naturais, e não tanto pela perda dos atrativos da natureza ou dos seus valores intrínsecos. Os representantes dessa segunda corrente utilizam a palavra "natureza", porém falam mais precisamente de "recursos naturais", ou até mesmo "capital natural" e "serviços ambientais" [...] esse credo é atualmente um movimento de engenheiros e economistas, uma religião da utilidade e da eficiência técnica desprovida da noção de sagrado.

É preciso ter cuidado para que não se tenha uma noção romântica da natureza, uma noção "rousseauniana" por assim dizer. Como bem frisou Martínez Alier, essa eco-eficiência pode ser expressa por uma operação matemática simbólica: eco-eficiência = empresa + desenvolvimento sustentável. Essa fé cega na técnica, que tudo pragmatiza, acaba por ter uma visão utilitarista da 
natureza, pois ao quantificá-la e mensurá-la, como fazem engenheiros e economistas, convertea em serviço, em capital (principalmente) e em recurso. $O$ valor intrínseco é modificado em valor de troca; o desenvolvimento sustentável é atingido com a negação do ócio através da indústria, uma vez que os impactos ambientais são resumidos em retorno aos acionistas. Passemos, agora, à letra L, que significa Legislação como base: melhoria contínua.

Atuar em plena conformidade com a legislação e demais requisitos aplicáveis e buscar melhorias contínuas que nos levem, em todos os territórios de atuação, a superar progressivamente padrões internacionais em saúde e segurança, condições de trabalho, gestão ambiental, relações trabalhistas e respeito aos direitos humanos (VALE, 2009a, p. 1).

Cabe destacar que as notificações do Ministério Público do Trabalho, no ano de 2007, levaram a empresa a rever sua política de terceirização ${ }^{8}$ e contratação de fornecedores da cadeia produtiva. Em agosto do referido ano, a Vale anunciou "o corte no fornecimento para usinas que não respeitam as legislações ambientais e trabalhistas em vigor no Brasil". A decisão atingiria a Companhia Siderúrgica do Pará (Cosipar) e a Usina Siderúrgica de Marabá S/A (Usimar) ${ }^{9}$. A Vale informou que estará monitorando de forma mais efetiva seus fornecedores $\mathrm{e}$ terceirizados, com o objetivo de "que as leis e as convenções de direitos humanos sejam incorporadas à cadeia de fornecimento e ao ambiente de trabalho" (VALE, 2009c, p. 95).

Em Moçambique o Projeto de Carvão Moatize que irá explorar carvão metalúrgico e carvão técnico deslocará aproximadamente 1.100 famílias. Com efeito, várias serão as conseqüências desse projeto: alto custo social, perda de terras, "impactos na saúde devido à poeira e ao ruído, mudanças radicais nas culturas tradicionais como exumação de corpos e deslocamento de atividades econômicas locais" (ORGANIZAÇÕES et al, 2010, p.127). Além disso, a Vale pretende exportar minério de ferro para a China e Omã. Com a produção de 1 milhão de toneladas por ano a serem exploradas das minas no distrito de Monapo, província de Nampula, espera-se arrecadar US\$ 100 milhões. As minas possuem um período estimado em 28 anos e a geração de 800 postos de trabalho ${ }^{10}$. Avancemos à letra 0 , que significa Organização e Disciplina.

Trabalhar de forma organizada e disciplinada, adotando práticas rigorosas de planejamento, execução, monitoramento e ação corretiva, buscando o uso responsável e eficiente dos recursos naturais. Em termos de responsabilidade sobre o produto, incentivar o uso, re-uso, reciclagem e disposição final dos nossos produtos e sub-produtos, incluindo, quando estiver ao alcance da Vale, o design responsável (VALE, 2009a, p. 1, os grifos são nossos).

Note-se que a Vale, uma representante do evangelho da eco-eficiência, tal como concebido por Martínez Alier (2007), emprega o termo recursos naturais em vez de natureza, reafirmando assim que a sua organização, disciplina, planejamento, execução e monitoramento de atividades traduz-se na eficiência com que trata e utiliza da natureza, que por sua vez é vista como recurso, um meio para atingir um fim. Passemos à letra $R$, que significa: Respeito e Ética nos Negócios.

Trabalhar de forma ética e respeitosa em todos os países e regiões onde atuamos. Buscar excelência na nossa governança corporativa, nos processos operacionais, na qualidade dos produtos e relacionamentos com partes interessadas. Difundir a atuação sustentável na nossa cadeia
8 É bom deixar claro que a adoção de políticas de terceirização de empregos se reflete em uma estratégia econômica que retira a responsabilidade da empresa e precariza as relações de trabalho e emprego.

${ }^{9}$ Consultar Vale do Rio Doce anuncia corte de fornecimento a siderúrgicas (23/08/2007) http://www.reporterbrasil.org.br/ exibe.php?id=1153.

10 http://www.macauhub.com.mo/ pt/news.php?|D=9472
Geografia Ensino \& Pesquisa, v. 15, n.3, p. 7-26, set./dez. 2011

Ribeiro Junior, J. A.; Sant'Ana Júnior, H. A.

ISSN 2236-4994 
11 A assessoria jurídica do STEFEM está movendo ações cobrando da Vale e empresas terceirizadas as denominadas horas in itinere devidas aos trabalhadores, as quais, de acordo com o advogado Guilherme Zagallo, a Vale se nega a pagar e ainda obrigava as empresas terceirizadas a também não pagarem. [...] Para o causídico, as ações tem tido sua importância, pois já obrigou a Vale mudar de comportamento com relação às horas in itinere modificando 0 horário de chegada e saída dos ônibus. Para os reclamantes, o início de uma vitória, uma vez que eram obrigados a esperar entre 50 a 60 minutos no local de trabalho, o normal é 15 minutos, quando poderiam estar com seus familiares (STEFEM, 2010).

$12 \mathrm{http}: / /$ blogdosakamoto.uol. com.br/

Geografia Ensino \& Pesquisa, v. 15, n.3, p. 7-26, set./dez. 2011

A politica de desenvolvimento sustentável da produtiva. Adotar padrões e práticas globais de sustentabilidade, respeitando a soberania de cada país e a legislação local (VALE, 2009a, p. 1).

Mais uma postura do "ecologicamente correto" da Vale. Só quem conhece o habitus ambiental da Vale é que pode contradizê-la na prática. Por exemplo: porque não são registrados os mortos por atropelamento ao longo da ferrovia (numa média de um morto por mês) como bem informou Cláudio Bombieri (VIAS DE FATO, 2010)? Ou quando a Vale e suas empresas terceirizadas não pagam as horas in itinere dos trabalhadores ${ }^{11}$ (NOTÍCIAS STEFEM, 2010, p.8)? Sem falar das siderurgias vinculadas ao Projeto Carajás que são abastecidas pela extração em larga escala de madeiras. Como a Vale pode falar em ética uma vez que tal palavra não devolve as vidas que foram subtraídas em suas ferrovias?

Em Parauapebas (PA), a Justiça do Trabalho condenou a Vale a pagar $\mathrm{R} \$ 300$ milhões em virtude dos trabalhadores diretamente contratados pela Vale ou por empresas que prestam serviço a ela (terceirizadas) gastarem um mínimo de duas horas de deslocamento para ir e voltar às minas, valor este que não era remunerado ou descontado da jornada de trabalho. A empresa declarava que não era sua responsabilidade o transporte dos trabalhadores, haja vista é um espaço público fora dos seus limites, e que, portanto, devia ser feito pelo sistema público. Ela apenas esqueceu-se que o seus trabalhadores são privados, e não públicos, o que reafirma a competência da Vale a questão das horas in itinere.

Em todo caso, dos $R \$ 300$ milhões, $R \$ 100$ milhões são por danos morais coletivos e mais $\mathrm{R} \$ 200$ milhões por dumping social. O juiz Jônatas Andrade acatou ação do procurador José Adilson Pereira da Costa do Ministério Público do Trabalho contra a empresa por considerar que a gigante da mineração estava lucrando indevidamente sobre a exploração indevida de seus empregados e prestadores de serviço na região da província mineral de Carajás. Com isso a Vale teria economizado um valor superior a $\mathrm{R} \$ 200$ milhões nos últimos cinco anos, praticando concorrência desleal em detrimento da qualidade de vida dos seus empregados. Esse valor decorrente de dumping social deverá ser depositado no Fundo de Amparo ao Trabalhador como reparação à sociedade e ao mercado. Os $\mathrm{R} \$ 100$ milhões relativos ao dano moral coletivo, segundo a sentença, terão que ser revertidos à própria comunidade afetada (o que inclui todos os municípios da província mineral de Carajás e não apenas Parauapebas) através de projetos derivados de políticas públicas de defesa e promoção dos direitos humanos do trabalhador ${ }^{12}$.

Segundo Lúcio Flávio Pinto, em matéria intitulada "Mais uma vez, é a Vale quem ganha em Carajás", no acordo promovido em Belém, pela justiça do trabalho, a empresa finalmente reconheceu 0 direito dos trabalhadores. Eles receberão diariamente um adicional pelos 44 minutos gastos até a mina de ferro de N4, 54 minutos até a jazida de cobre do Sossego e 80 minutos até a mina de manganês do Azul. A empresa terá também de quitar o débito acumulado nos últimos 42 meses (crédito em favor dos empregados retroativo a fevereiro de 2007, provavelmente data-base). Pelo acordo, a Vale também promoverá ações sociais no montante mínimo de $\mathrm{R} \$ 26$ milhões (pouco mais de 10\% do valor definido na sentença judicial apenas pelo "dumping social"). Até março de 2012 implantará em Parauapebas uma unidade do Instituto Federal do Pará (antiga Escola Técnica) para cursos de mecânica e eletroeletrônica e, até março de 2011, uma escola modelo no município. 0 acerto, porém, foi ainda mais vantajoso para a Vale. Condenada inicialmente a desembolsar $\mathrm{R} \$ 300$ milhões, o total dos seus gastos ficará muito abaixo do mínimo que a súmula 34 do Tribunal Superior do Trabalho garante ao empregado nesses acordos, que é de $60 \%$ do valor da condenação, ou, nesse caso, $\mathrm{R} \$ 180$ 
milhões. Mesmo considerando apenas os $\mathrm{R} \$ 200$ milhões atribuídos como pena à prática do "dumping", o pagamento do itinerário dos funcionários será bem inferior aos R 154 milhões de diferença entre as ações sociais, de $\mathrm{R} \$ 26$ milhões, e a pena legal.

\section{Catalisador do desenvolvimento local}

Até 0 presente momento pudemos perceber que o operador sustentável da Vale é, verdadeiramente, um operador, no mínimo, questionável. Isso porque opera e converte a natureza em um recurso; e objetiva tornar sustentável a agregação de valor, o retorno para os acionistas e a forma como ela desenvolve a sua atividade mineradora (RIBEIRO JUNIOR; SANT'ANA JÚNIOR, 2010).

Após reduzir a problemática ambiental a um problema tecnológico (como se essa tecnologia não fosse "filha" da matriz de racionalidade crematística), a Vale se apresenta como um "Catalisador do desenvolvimento local", ao informar que quer "ir além da gestão dos impactos de nossas operações e projetos, contribuindo voluntariamente e através de parcerias com governo e sociedade para o desenvolvimento L.O.C.A.L." (VALE, 2009a, p. 2). De início, percebe-se que a Vale se auto-intitula uma empresa que acelera o desenvolvimento local. Como a maioria das pessoas possui uma noção positiva do desenvolvimento, isto já qualifica (erroneamente) de antemão a Vale como instituição que produz benefícios para a localidade na qual ela se instala. Mas o ponto que é preciso alertar é sobre a ideia de desenvolvimento. Segundo Porto-Gonçalves (2006, p. 81):

Des-envolver é tirar o envolvimento (a autonomia) que cada cultura e cada povo mantém com seu espaço, com seu território; é subverter o modo como cada povo mantém suas próprias relações de homens (e mulheres) entre si e destes com a natureza; é não só separar os homens (e mulheres) da natureza como, também, separá-los entre si, individualizando-os. Não deixa de ser uma atualização do princípio romano - divide et impera - mais profunda ainda, na medida em que, ao des-envolver, envolve cada um (dos desterritorializados) numa nova configuração societária, a capitalista.

Sim, essa é a essência do desenvolvimento: é des-envolver. É retirar a autonomia que cada cultura mantém com seu lugar. Por isso, seria interessante pensar numa perspectiva de pós-desenvolvimento (ESCOBAR, 2005): isso significa, ao pé da letra, tornar póstumo o desenvolvimento, abdicar dessa palavra canonizada pelas ciências e pelo discurso políticoideológico, seja ele da direita ou da esquerda. Dessa forma, numa ótica pós-desenvolvimentista, daríamos espaço a racionalidades econômicas, ecológicas e culturais que estão do outro lado da margem, que não são modernas, ou seja, não obedecem à lógica do capital: tal como a racionalidade econômica dos camponeses, a racionalidade ecológica dos indígenas, dentre outros.

E a Vale, como ela mesma se intitula catalisadora do desenvolvimento, não foge a esta assertiva. Nos lugares onde ela se instalou, especificamente em São Luís, ela subverteu a relação que os habitantes de determinados bairros (próximos ao Porto do Itaqui, como é o caso do Alto da Esperança) tinham com a Natureza, com o seu habitat, acabando por agravar a situação urbana e social da capital maranhense. Ao se instalar em São Luís, a Vale desterritorializou inúmeros maranhenses direta e indiretamente. Diretamente aqueles que

Geografia Ensino \& Pesquisa, v. 15, n.3, p. 7-26, set./dez. 2011

Ribeiro Junior, J. A.; Sant'Ana Júnior, H. A. 
habitavam o local onde a empresa se alojou, indiretamente os camponeses que deixaram 0 interior maranhense em busca de emprego e melhores oportunidades. Depois de desterritorializados foram inseridos precariamente em uma nova configuração societária, a do capital moderno (RIBEIRO JUNIOR; SANT'ANA JÚNIOR, 2010). Não olvidemos que modernizar é colonizar, como nos ensina Edgardo Lander, e, portanto traz todas as implicações possíveis por se "estar na moda".

Mas, continuemos nossa análise letra por letra, iniciando pela letra L, que significa na sigla: Licença social. "Buscar o reconhecimento, a consulta e o envolvimento prévio à implantação de novos empreendimentos dos stakeholders locais" (VALE, 2009a, p. 2). Interessante perceber aqui que a licença, não é social, pois não é a sociedade em si que a concede, mas sim os representantes dessa sociedade, que não atendem aos interesses da sociedade do qual representam: o que desqualifica a "licença social" da Vale.

Tomemos o exemplo de Belo Monte na qual a Vale, Andrade Gutierrez, Camargo Corrêa, Odebrecht, Votarantim, GDF Suez e Alcoa estão interessadas na construção. A Usina hidrelétrica de Belo Monte "geraria apenas 39\% dos $11.181 \mathrm{MW}$ de potência divulgados, devido à grande variação da vazão do rio" (ORGANIZAÇÕES et al, 2010, p.24). Caso a UHE Belo Monte seja realmente efetivada os impactos ambientais em torno da flora e fauna terrestre e aquática serão gravíssimos, com destaque para a diminuição do número de peixes existentes no Rio Xingu. Mais: os 24 grupos indígenas serão diretamente afetados em virtude dessa obra faraônica que vem sendo chamada de "Belo Monstro" (MAGALHÃES; HERNANDEZ, 2009).

O MME, o IBAMA e o governo federal violaram direitos humanos ao não realizarem as Oitivas (consultas) Indígenas, obrigatórias pela legislação brasileira e pela Convenção 169 da OIT, que garantem aos indígenas o direito de serem informados sobre os impactos da obra e de terem sua opinião ouvida e respeitada. [...]

A Licença Prévia foi emitida pela presidência do IBAMA apesar do parecer contrário dos técnicos do órgão. Alguns técnicos pediram demissão, outros se afastaram do licenciamento e outros ainda assinaram um parecer contrário à liberação das licenças para a construção da usina (ORGANIZAÇÕES et al., 2010, p. 24).

Aqui cabe reafirmarmos: paralelo ao envolvimento da empresa está o des-envolvimento, ou seja, a empresa se "autonomiza", toma para si o território das comunidades (no caso de Belo Monte, os grupos indígenas), promovendo uma verdadeira razia contra a cultura local. Ainda: onde está a licença social se os grupos indígenas que vivem diretamente da floresta e do rio não foram consultados? E quanto aos mais de 100 mil pessoas que, seduzidos pela obra faraônica, irão causar desmatamento e pressão por recursos numa região que tem cerca de $70 \%$ do seu território protegido (MAGALHÃES; HERNANDEZ, 2009)?

Passemos à letra 0 , que denota: Ordenação para o desenvolvimento. "Contribuir para a construção de planos e ações específicos voltados para o desenvolvimento ordenado e sustentável das regiões onde atuamos" (VALE, 2009a, p. 2). Difícil não lembrar do lema de August Comte: "Ordem e Progresso", tão visível na bandeira do Brasil. Na assertiva da Vale 0 progresso é "substituído" pelo des-envolvimento, que precisa de ordem para ser efetivado.

Sendo assim, se ordenação é des-envolvimento, desordem é envolvimento. Estamos diante, portanto, de um complexo jogo de palavras. A ordenação de que nos fala a Vale é direcionada para a reprodução do capital e para a retirada de autonomia da população com relação a seu território. Isso é des-envolvimento. Para tanto, esta ordem, a ordem do capital moderno, precisa ser mantida, pois desordem é regresso. Então, a Vale aponta que contribui para a construção de 
planos e ações específicos voltados para o desenvolvimento ordenado, ou seja, para a retirada ordenada da autonomia territorial das comunidades, consequentemente, ela tenderá a sustentar tal ordem de desenvolvimento.

Seguindo nosso "alfabeto valiano" temos a letra C que expressa: Comunicação e engajamento. "Manter comunicação e diálogo amplo, transparente, permanente e estruturado com stakeholders, respeitando a diversidade e as culturas das regiões onde atua, e considerando suas demandas nas decisões gerenciais da empresa" (VALE, 2009a, p. 2). De fato, com as partes interessadas (stakeholders), principalmente os acionistas, a Vale com certeza deve manter um diálogo amplo, transparente, permanente e estruturado. Todavia o respeito à diversidade e as culturas das regiões onde ela se estabelece é altamente questionável.

É o caso da Companhia Siderúrgica do Atlântico. Neste exemplo a Vale detém a parte minoritária da joint venture com a ThyssenKrupp (27\% e $73 \%$ respectivamente) para produção de 5,5 milhões de toneladas/ano de placas de aço (tal planta siderúrgica é a maior da América Latina), utilizando carvão mineral da Colômbia (4 milhões de toneladas/ano) e localizada no município de Itaguaí (ORGANIZAÇÕES et al, 2010). Formam o conglomerado:

Uma usina siderúrgica integrada, uma termoelétrica para a geração de 490 MW de energia elétrica e um porto com dois terminais composto por uma Ponte de Acesso de $3,8 \mathrm{Km}$ e um Píer de $700 \mathrm{~m}$ que atravessa o manguezal e 0 oceano. Toda a produção do conglomerado será destinada à exportação: 2 milhões de toneladas para a Alemanha, para serem processadas, e cerca de 3 milhões para os mercados dos Estados Unidos, México e Canadá (ORGANIZAÇÕES et al, 2010, p.68).

Não obstante, a área onde se localiza tal empreendimento, tem impactado pelo os pescadores artesanais. Os atingidos, por meio da Carta aberta à sociedade sobre a Ocupação na Secretaria de Estado do Ambiente pela comunidade de Santa Cruz/RJ, repudiaram a falta de compromisso com as instituições, com as comunidades, com os pescadores, com os trabalhadores, e com as próprias leis do Estado Democrático de Direito, por parte do senhor Carlos Minc ao não comparecer em Audiências Públicas na Assembleia Legislativa do Rio de Janeiro (ALERJ) convocada pela Comissão Especial que investiga o caso TKCSA ${ }^{13}$.

Por outro lado, o Ministério Público do Rio denunciou a Usiminas por apresentar auditoria ambiental considerado falsa e omissa sobre a operação parcial da CSA (Companhia Siderúrgica do Atlântico) Em matéria publicada no jornal Folha de São Paulo (01/07/2011), Promotoria denuncia Usiminas por relatório irregular sobre CSA, O MP aponta que o relatório seria usado no processo de licenciamento da siderúrgica, instalada na zona oeste do Rio.

Também foram denunciadas quatro pessoas que assinaram o documento: Bruno Menezes de Melo, Ricardo Salgado e Silva, Marta Russo Blazek e Monica Silveira e Consta Chang.

A Usiminas foi escolhida para fazer auditoria ambiental na CSA após a siderúrgica ser denunciada por crimes ambientais pelo derramamento de ferro-gusa em poços ao ar livre, o que provoca, segundo o MP, danos à saúde da população vizinha.

Mas de acordo com a Promotoria, a empresa forneceu na auditoria uma informação falsa e foi omissa em dois pontos.

O Ministério Público informou que os denunciados afirmaram no relatório de auditoria ambiental que não foi possível, durante a inspeção, analisar a cambagem de ferro-gusa no poço de emergência. A Promotoria diz que
$13 \quad$ Disponível em http://racismoambiental.net.br/20 11/08/carta-aberta-a-sociedadesobre-a-ocupacao-na-secretariade-estado-do-ambiente-pelacomunidade-de-santa-cruzrj/
Geografia Ensino \& Pesquisa, v. 15, n.3, p. 7-26, set./dez. 2011

Ribeiro Junior, J. A.; Sant'Ana Júnior, H. A. 
14 O BNDES destinou a Vale, em 2008, um empréstimo da ordem de R $\$ 7$ bilhões. No entanto, como já foi citado aqui, a Vale, se valendo da recessão econômica, demitiu seus trabalhadores. documentos fornecidos pela própria CSA apresentam a informação referentes ao dia da visita dos técnicos da Usiminas à siderúrgica.

0 órgão apontou ainda que os técnicos não mencionaram no relatório que a CSA excedeu o limite de emissão de SO2 (dióxido de enxofre) em 27 de janeiro e 10 de fevereiro. A segunda omissão foi a falta de uma análise comparativa entre a tecnologia de controle de poluentes usada na siderúrgica do Rio e as utilizadas em todo o mundo.

\section{Outro lado}

Em nota, a Usiminas afirmou que elaborou o relatório de auditoria sobre questões ambientais da CSA a pedido das autoridades ambientais do Estado do Rio.

A empresa disse também que ainda não foi citada e não teve acesso ao teor das argumentações do Ministério Público (http://www1.folha.uol.com.br/cotidiano/937588-promotoria-denunciausiminas-por-relatorio-irregular-sobre-csa.shtml).

Some-se a isso a alta quantidade de poluentes emitidos (229.758 toneladas monóxido de carbono e 21.540 toneladas de dióxido de enxofre) pari passu à diversificação ecossistêmica da área que compreende desde florestas a restingas - como a da Marambaia - e manguezais (ORGANIZAÇÕES et al, 2010). Além disso: "Podem ser encontradas áreas remanescentes da Mata Atlântica, principalmente na Serra do Mar, considerada atualmente uma das 25 áreas mais importantes para a conservação da biodiversidade em todo o mundo (ORGANIZAÇÕES et al., 2010, p. 69).

Em seguida temos a "letra A", que exprime: Alianças Estratégicas. "Estabelecer alianças com atores estratégicos de diferentes setores - público, privado e sociedade civil - para a articulação e planejamento de programas de desenvolvimento local integrado" (VALE, 2009a, p. 2). Não olvidemos que aliança simboliza união, um pacto, um acordo entre, no mínimo, duas partes. Sendo assim, bem como a Vale merece ser criticada, o Estado também merece, em outro momento (já que não é o hipocentro do nosso trabalho) uma análise mais radical a respeito dessa aliança com empresas. Estratégia também merece uma anotação, já que ela se preocupa essencialmente com "a gestão [administração] da guerra e com a segurança pública" (VESENTINI, 2007, p. 10). De fato, no capitalismo vivemos um eterno período de crises e guerras, sendo necessárias estratégias que garantam a sobrevivência no seio da relação desarmônica cognominada competição. Então, o que esperar de uma aliança estratégica entre a Vale e o Estado? Possivelmente um pacto, uma união, um casamento, no qual ambos tornam seus olhos para a gestão da guerra, mas esquecem-se da "segurança pública", ou seja, não garantem as "benesses da guerra" pelo capital. Dessa forma, quando se configura uma aliança estratégica entre Estado e Empresa (Vale) torna-se muito mais fácil aliar interesses, guerrear contra a sociedade civil para que a autonomia local seja desintegrada, des-envolvida.

Com efeito, dificilmente a Vale seria a empresa que é hoje se não fosse o Estado brasileiro. Desde isenções fiscais concedidas por governos estaduais, municipais, passando pelo financiamento do BNDES ${ }^{14}$ (que financia o plano qüinqüenal), o Estado brasileiro sempre desempenhou da melhor maneira possível suas políticas governamentais que favoreceram direta e indiretamente o desempenho econômico da Vale, bem como fortaleceu as bases para sua internacionalização (GODEIRO et al., 2007).

No Brasil, o modo e a escala de operação da Vale, baseados em grandes projetos voltados à produção de enormes excedente para atender prioritariamente ao mercado internacional, exige a intermediação do Banco Nacional de Desenvolvimento Econômico e Social (BNDES), o principal 
instrumento para financiar o modelo econômico nacional. O BNDES participa simultaneamente do controle acionário da Companhia e no fornecimento de fundos para investimentos e para capital de giro da Vale. É através do BNDES e da BNDES Participações, subsidiária do Banco para o mercado de capitais, que o Estado ainda mantém uma herança do tumultuado processo de privatização da companhia (ORGANIZAÇÕES et al., 2010, p. 22).

Depois que a companhia foi privatizada pelo então presidente Fernando Henrique Cardoso, a maior parte das ações passou para o controle da Valepar:

[...] uma sociedade financeira criada por empresas interessadas em comprar o pacote majoritário da Vale. Em 2007, a Valepar detinha 53,3\% do capital ordinário da empresa, sendo o BNDESPar responsável por 6,8\% das ações. 0 restante encontrava-se distribuído entre investidores diversos, sendo $27 \%$ não brasileiros e $12,9 \%$ brasileiros (ORGANIZAÇÕES et al., 2010, p. 19).

Todavia, apesar do governo brasileiro possuir somente 3,3\% das ações, tais ações são especiais, pois são golden share, o que dá direito a veto em decisões estratégicas da companhia. Essas ações preferenciais de classe especial "titularidade da União Federal, que dão ao Estado brasileiro os mesmos direitos que possuem os detentores de ações preferenciais Classe A [...] (ORGANIZAÇÕES et al., 2010, p. 19).

As ações de ouro significam poder de veto nas decisões relativas a: 1 . alteração da denominação social da companhia. 2. mudança da sede social. 3. mudança do nosso objeto social relativamente à exploração de jazidas minerais. 4. liquidação da empresa. 5. qualquer alienação ou encerramento das atividades de uma ou mais das seguintes etapas dos sistemas integrados da exploração de minério de ferro, jazidas minerais, depósitos de minério, minas, ferrovias, portos e terminais marítimos. 6 . qualquer modificação dos direitos atribuídos às espécies e classes das ações de emissão da Companhia. 7. qualquer modificação de quaisquer dos direitos atribuídos pelo Estatuto Social à ação preferencial de classe especial (ORGANIZAÇÕES et al., 2010, p. 19).

Este quadro geral da relação entre a Vale e o Estado brasileiro dá uma boa dimensão das relações existentes entre esses dois grandes atores que atuam no campo político-econômico e socioambiental. Os interesses que estes atores possuem entre si, dificilmente materializam-se em interesses da sociedade.

Por fim, mas não menos importante, na parte do catalisador do desenvolvimento local, o "alfabeto valiano" encerra com a letra L que expressa: Legado Regional.

Trabalhar de forma articulada para gerar um legado positivo nas regiões onde a Vale atua, buscando a maximização do desenvolvimento socioeconômico através do ciclo mineral, contribuindo com a diversificação econômica, com o desenvolvimento social e com a promoção da conservação e recuperação do meio ambiente (VALE, 2009a, p. 2).

Aquilo que a Vale transmite para a sociedade maranhense, em especial a ludovicense, a sua herança, são os problemas referentes à submoradia, deficiência de saneamento básico e poluição, entre outros. A maximização da retirada da autonomia da sociedade e da economia é, paradoxalmente, uma forma de tratar o ambiente como um meio, um meio para atingir um fim.

Geografia Ensino \& Pesquisa, v. 15, n.3, p. 7-26, set./dez. 2011

Ribeiro Junior, J. A.; Sant'Ana Júnior, H. A.

ISSN 2236-4994 
15 Instituto Brasileiro de Análise Sociais e Econômicas - Ibase incluiu em sua linha programática o tema da responsabilidade social e ética nas organizações, com 0 objetivo de consolidar parcerias com organizações no Brasil e, nos demais países da América Latina, e cobrar uma postura ética, práticas responsáveis e transparência no meio empresarial e nas organizações da sociedade civil. Para tanto, o lbase está desenvolvendo dois projetos: 0 de Responsabilidade Social das Empresas (RSE) e Balanço Social. De acordo com a metodologia do balanço social, as empresas e organizações devem apresentar as informações em um padrão mínimo, destacando os dados que possam ser expressos em valores financeiros, ou de forma quantitativa, aquilo que elas investem em educação, saúde, cultura, esportes e meio ambiente (GRIGATO; RIBEIRO, 2006, p. 12). De acordo com o referido balanço social, a quantia total (absoluta), aplicada em investimentos de ordem ambiental, cresceu expressivamente no período de 1998-2007, passando de 17 milhões para 761 milhões de reais, ou seja, um aumento de quatro vezes por ano. Aos olhos dos leigos isso pareceria uma maravilha, e de prontidão eles diriam que a Vale investe absurdamente dada à prova concreta. Todavia, em se analisando os valores relativos acerca da receita líquida da empresa, é possível ter uma dimensão da expressividade dos "Investimentos em Meio Ambiente": $0,50 \%$ em 1998; 0,43\% em 1999; 1,16\% em 2000;

Geografia Ensino \& Pesquisa, v. 15, n.3, p. 7-26, set./dez. 2011

A politica de desenvolvimento sustentável da

\section{Agente global de sustentabilidade}

Chegamos à parte final da Política de Desenvolvimento Sustentável da Vale. Até aqui já temos uma boa noção do que significa essa política: visa retirar a autonomia que as comunidades possuem e mantém com seu espaço geográfico (socionatural). Nesta última parte, a Vale se intitula um Agente Global de Sustentabilidade, em suas próprias palavras:

A atuação G.L.O.B.A.L. parte do reconhecimento de que determinados temas globais de sustentabilidade podem afetar nossos negócios, e de que a Vale - como uma das empresas líderes globais no setor de Mineração pode contribuir para a promoção internacional de boas práticas de sustentabilidade (VALE, 2009a, p. 2).

De fato, a atuação da Vale é global, assim como também são seus impactos. Mais do que reconhecer-se enquanto tal, mais do que apenas se preocupar com a capacidade que um determinado tema pode afetar os seus negócios, especialmente o setor de mineração, as "boas práticas de sustentabilidade" da Vale sustentam apenas os seus negócios; para tanto uma verdadeira prática de sustentabilidade requer uma teoria sustentável, que implica, por conseguinte uma racionalidade ambiental, ao contrário da racionalidade crematística da qual está impregnada a referida empresa (RIBEIRO JUNIOR; SANT'ANA JÚNIOR, 2010).

Observe-se que ao intitular-se um agente global de sustentabilidade, a Vale constrói e concebe um mundo que negligencia práticas e perspectivas baseadas-no-lugar (ESCOBAR, 2005). Com efeito, torna-se praticamente impossível pensar-se em sustentabilidade ambiental, tampouco em desenvolvimento, uma vez que, as práticas ecológicas e econômicas gestadas no capitalismo e na modernidade são por si só insustentáveis e des-envolvimentistas (no sentido de retirada de autonomia da dimensão local). Gostaríamos de abdicar de analisar a Política de Desenvolvimento Sustentável utilizando como método o "alfabeto valiano", mas ela nos faz mais uma vez utilizar deste meio.

A letra G do "alfabeto valiano" aparece-nos pela primeira vez e significa: Garantia de Transparência. Em suas palavras: "Garantir transparência quanto às políticas, procedimentos, práticas e desempenho da empresa em relação aos aspectos sociais, ambientais, econômicos e de governança junto às partes interessadas globalmente" (VALE, 2009a, p. 2). Transparência, com toda certeza, não é uma palavra que combina com a Vale; se fosse assim porque ela haveria de omitir informações extremamente relevantes do sítio do lbase, no que tange aos investimentos para tornar mínimo resíduos e aumentar a eficácia na utilização dos recursos naturais ${ }^{15}$ ? Onde estão os "raios de luz que atravessam" a Vale quando ela não disponibiliza no balanço social, as informações relativas ao exercício da cidadania? Da mesma forma que ela deturpa a sustentabilidade, vemos a Vale deturpar o conceito de transparência confundido-o com o de opacidade.

A letra $L$ que é uma das letras que a Vale mais gosta, talvez por ser a letra que no alfabeto português principia a palavra lucro; exprime aqui: Liderança. "Buscar liderança nas discussões internacionais setoriais ligadas aos aspectos do desenvolvimento sustentável mais afeitos aos nossos negócios e operações" (VALE, 2009a, p. 2). 0 objetivo é, então, liderar as discussões internacionais relacionadas ao desenvolvimento sustentável mais habituados e acostumados aos negócios e operações da referida empresa. Observe-se, todavia, que a Vale, em momento algum, busca liderar as discussões acerca dos impactos ambientais que ela causa, da pressão que ela exerce sobre as comunidades; são sempre os negócios e as operações que geram lucro 
para seus acionistas que direcionam a "racionalidade valiana" (RIBEIRO JUNIOR; SANT'ANA JÚNIOR, 2010).

Sem falar que essa "liderança é dupla": se de um lado ela "busca liderar as discussões internacionais" ela também pressiona lideranças que se opõem a quaisquer que sejam seus projetos. É o que vem ocorrendo na Baía de Sepetiba (RJ) em virtude da aliança entre a Vale e a ThyssenKrupp para a construção da companhia Siderúrgica do Atlântico.

\begin{abstract}
Devido às constantes ameaças de morte feitas pelas milícias locais aos pescadores da Baía de Sepetiba que se opunham ao projeto, um pescador, sob risco de perder a sua vida, teve que se refugiar. A pressão sobre as lideranças se acentuaram ainda mais quando as acusações de que alguns dos seguranças contratados pela empresa eram contratados por grupos milicianos ficaram claras na audiência pública da Assembléia Legislativa do Rio de Janeiro. Um pescador está refugiado desde fevereiro de 2009. Atualmente vive num local escondido e distante da Baía de Sepetiba, sendo protegido pelo Programa Federal de Proteção aos Defensores dos Direitos Humanos (ORGANIZAÇÕES et al., 2010, p. 77).
\end{abstract}

Por conseguinte, a letra 0 expressa: Observação de tendências. "Monitorar e antecipar tendências em temas globais de sustentabilidade" (VALE, 2009a, p. 2). Isso significa que as tendências em sustentabilidade devem ser observadas. Para fazer isso, a Vale monitora, digamos, o "Observatório Ambiental", a situação ambiental mundial, já que ela se declara uma "agente global de sustentabilidade". Isso explica em parte a crença da Vale no evangelho da ecoeficiência; isso porque a questão ambiental é, em sua visão, uma questão tecnológica, como vimos anteriormente. Esse raciocínio é muito simplório, é um verdadeiro sofisma, pois se nós estamos questionando essa racionalidade econômica, que produziu essas técnicas e tecnologias, como é que estas técnicas e tecnologias podem solucionar o desafio ambiental se elas [as técnicas e tecnologias] são fruto da racionalidade crematística, se são um "problema do problema"? A questão ambiental está como vemos, para além da simples tecnologia.

Todavia, na cidade maranhense de Açailândia, instalou-se no ano de 20050 empreendimento Ferro Gusa Carajás (FGC). O problema é que a empresa controlada pela Vale, que destina-se a sustentar a siderúrgica da Vale em Marabá, através da produção de carvão vegetal, se estabeleceu ao lado do assentamento Califórnia, com mais de 1.800 moradores assentados há 13 anos. Sabe-se que a atividade siderúrgica é uma das mais poluentes e, não é difícil imaginar, o quanto os moradores de Califórnia estão sofrendo com tal atividade por respirarem diariamente as fumaças provenientes das chaminés. Some-se a isso o fato de que a Vale nem sempre monitorou a qualidade do ar.

\begin{abstract}
A medição da qualidade do ar nem sempre foi efetiva. No Plano de Gestão da Qualidade, o artigo previa a execução de um programa de avaliação da qualidade do ar e de acompanhamento da operação do queimador. Conforme o Relatório de Controle Ambiental, para a avaliação da qualidade do ar deveria ser monitorado o parâmetro 'partículas totais em suspensão' (PTS). Para isso, deveria ser instalado um equipamento do tipo Hi-Vol a jusante da área do empreendimento, com relação à direção predominante dos ventos (ORGANIZAÇÕES et al., 2010, p. 55).
\end{abstract}

Entre 2005 e 2009, os moradores do assentamento Califórnia respiraram a fumaça venenosa emitida por todos os fornos em funcionamento. Não precisa ser médico para imaginar os principais problemas que afetam a população: problemas cardiorrespiratórios, epidérmicos,
$0,77 \%$ em 2001; 0,7\% em 2002; $0,76 \%$ em 2003; $0,57 \%$ em 2004; $0,56 \%$ em $2005 ; 1,01 \%$ em 2006 e $1,15 \%$ em 2007. "Ressalta-se, ainda, que esses são valores agregados, representando a totalidade despendida pela empresa, pulverizadas para em todas as suas unidades no Brasil" (GRIGATO; RIBEIRO, 2006, p. 15, os grifos são nossos).
Geografia Ensino \& Pesquisa, v. 15, n.3, p. 7-26, set./dez. 2011

Ribeiro Junior, J. A.; Sant'Ana Júnior, H. A.

ISSN 2236- 4994 
oftalmológicos, dentre outros. Por fim, foi somente em 2008 que dois medidores foram instalados. No entanto, até outubro de 2008, a Secretaria Estadual de Meio Ambiente (SEMA) não havia sequer recebido um relatório oficial acerca da poluição do ar (ORGANIZAÇÕES et al., 2010).

A letra B significa no "alfabeto valiano": Boas Práticas. "Adotar e desenvolver boas práticas globais de sustentabilidade e contribuir com sua difusão no setor" (VALE, 2009a, p. 2). Advirta-se que a Vale centra a questão nas práticas. Isso, obviamente ela não faz sem sapiência; ao centrarmos a discussão apenas nas práticas excetuamos a teoria que, de uma forma ou de outra, exerce pesada influência sobre as práticas. É como centrar as análises apenas nos efeitos e não nas causas. Um bom exemplo disso é o efeito estufa, em cuja discussão se concentram os esforços no efeito, e não nas causas que originaram o efeito.

Talvez as práticas da Vale no Canadá não sejam tão boas assim. Desde julho do ano passado (2009) o USW (United Steelworkers - o sindicato dos mineiros) com cerca de 3.500 trabalhadores está em greve em virtude da Vale, alegando a crise econômica mundial, querer extinguir direitos trabalhistas dos canadenses. Cabe destacar que:

Logo após o começo da greve, a Vale trouxe para Sudbury uma empresa de 'segurança' chamada AFI, que intimidou e assediou os trabalhadores sindicalizados da seção local 6500 do USW. A Vale tentou limitar o direito do sindicato de montar e manter piquetes. Ela está processando o sindicato e sua liderança, buscando indenizações milionárias, e lançando mão de uma tática sem precedentes: processar membros do sindicato individualmente. A Vale anunciou que operará as minas e usinas de processamento com "trabalhadores substitutos", isto é, com fura-greves! Seria a primeira vez desde a formação do sindicato em Sudbury que a direção da empresa tenta produzir durante um conflito trabalhista. A Vale inclusive já demitiu alguns grevistas e deixou bem claro que estes funcionários nunca voltarão a trabalhar lá (ORGANIZAÇÕES et al., 2010, p. 105-106, grifos nossos).

Esta política agressiva e anti-sindical da Vale trouxe conseqüências não apenas no que tange ao aspecto trabalhista, mas também na perspectiva ambiental. A mineradora Inco, que foi comprada pela Vale em 2006, e que originou a segunda maior produtora de níquel do mundo, também não adotou boas práticas globais de sustentabilidade:

O descaso da Vale Inco quanto ao cumprimento de exigências e condicionantes referentes aos direitos humanos teve seu auge em 2006 quando ela acabou sendo retirada do índice FTSE4GOOD (índice internacional de empresas com as melhores práticas de desenvolvimento sustentável). A companhia foi muito criticada pela poluição que causava e pela forma como tratava as populações indígenas e os trabalhadores. Residentes de Port Colborne, na província de Ontário, Canadá, afetados pela refinaria de níquel da Vale Inco, estão atualmente processando a empresa na maior ação judicial coletiva por danos ambientais na história do Canadá (ORGANIZAÇÕES et al., 2010, p. 120, grifos nossos).

Geografia Ensino \& Pesquisa, v. 15, n. 3, p. 7-26, set./dez. 2011

A politica de desenvolvimento sustentável da

A letra A também se repete no "alfabeto valiano". Aqui ela denota: atuação local, visão global. "Manter uma visão global de sustentabilidade alinhada com padrões de desempenho internacionais, e atuar localmente, garantindo a adaptação e 0 respeito às culturas e realidades locais" (VALE, 2009a, p. 2). É complicado pensar globalmente, até porque a globalização em si, não é global. Pensar de maneira mundial ou global é pensar como os príncipes da globalização, 
Estados e Empresas ocidentais que impõem um pensamento único/global dificultando alternativas regionais e locais que não condizem com a realidade; é uma verdadeira ocidentalização/estadunidização do mundo. Logo, se pensamos globalmente nossas práticas também serão influenciadas por essa visão única, global. Não esqueçamos que os grandes defensores do des-envolvimento sustentável são atores globais: Estados-Nações, europeus norte - ocidentais, empresas multinacionais (como a Vale) e ONG de alcance internacional. Então, se pensar globalmente é pensar unicamente, excetuando outras matrizes de racionalidade, como refletir acerca das culturas e realidades locais, haja vista des-envolvimento significa retirar a autonomia das culturas com seu espaço, da população com seu território/lugar? Talvez se deva pensar em outra globalização: uma globalização que não exclua a dimensão local ou a reduza à dimensão econômica para globalizar sob a égide de uma matriz cultural (RIBEIRO JUNIOR; SANT'ANA JÚNIOR, 2010).

O lugar, portanto, afirma-se em contraposição ao espaço global; quiçá devêssemos mesmo abdicar de falar em globalização: isso porque este fenômeno, gestado no capitalismo e na modernidade, tende a reproduzir os seus preceptores, ou seja, a globalização é capitalcêntrica (ESCOBAR, 2005). Se o hipocentro do capitalismo é a globalização, o epicentro da globalização é o desenvolvimento. Com efeito, são abalados (economias camponesas), às vezes até destruídos (economias socialistas), qualquer tipo, modelo ou possibilidade de desenvolvimento não capitalista. Superar a globalização, a modernidade, o capitalismo, em uma palavra, o capitalcentrismo, é um passo gigantesco na mudança de mentalidade e de habitus que ensejam racionalidades alternativas. Como diria Escobar (2005) "o lugar - como cultura local - pode ser considerado "o outro" da globalização". O referido autor propõe, de certa forma, uma centralidade do lugar, haja vista isso possibilita pensar de maneira distinta da perspectiva global, o meio ambiente, a cultura, a própria globalização, o capitalismo e a modernidade.

Por fim, a última letra da "Agente global de sustentabilidade" volta a ser a letra $L$ que significa: Legado para Gerações Futuras. Como não poderia deixar de ser ela termina com um som esperançoso, como é a sonoridade do desenvolvimento sustentável.

Trabalhar de forma articulada para contribuir com a construção de um legado positivo para as gerações futuras. Equilibrar os aspectos sociais, ambientais e econômicos dos nossos negócios de forma a gerar valor de longo prazo para acionistas, empregados, comunidades e governos nos países onde atuamos (VALE, 2009a, p. 2).

É interessante perceber como os agentes do capital, falam em gerações do futuro, mas na verdade sua preocupação e suas ações refletem apenas o aqui e 0 agora.

$\mathrm{O}$ ano de 2008 foi um ano de crise econômica, um período de turbulência no mercado financeiro mundial desencadeado pela crise imobiliária estadunidense, acarretando uma diminuição no ritmo econômico nos mais variados setores.

"O segmento mínero-metalúrgico demonstra diminuição dos investimentos e retração de pessoal. Notícias de demissões e férias coletivas já aparecem na Imprensa relacionadas às operações da VALE e da Alumar" (IMESC, 2008, p.28), "que não pensaram duas vezes" em demitir seus "peões". Todavia, a receita bruta da Vale no referido ano alcançou "US\$ 38,5 bilhões, valor $16,3 \%$ superior ao registrado no ano anterior, enquanto o lucro líquido foi de US\$ 13,2 bilhões" (VALE, 2009c, p. 5).

Diante desse cenário, a Vale agiu proativamente, realizando cortes na produção, prioritariamente em unidades operacionais de alto custo, e

Geografia Ensino \& Pesquisa, v. 15, n.3, p. 7-26, set./dez. 2011

Ribeiro Junior, J. A.; Sant'Ana Júnior, H. A.

ISSN 2236- 4994 
${ }^{16} \mathrm{http}: / / \mathrm{www} . \mathrm{dgabc} . \mathrm{com} . \mathrm{br} / \mathrm{def}$ ault.asp?pt=secao\&pg=detalhe \&c=3\&id=1685650 acesso em 27 de dezembro de 2009.

${ }^{17} \mathrm{http}: / /$ www.andes.org.br/impr ensa/ultimas/contatoview.asp? key $=5809$ acesso em 27 de dezembro de 2009.

18 "[...] é possível chegar a conhecimentos muito úteis para a vida e de achar, em substituição à filosofia especulativa ensinada nas escolas, uma prática pela qual, conhecendo a força e a ação do fogo, da água, do ar, dos astros, do céu e de todos os demais corpos que nos cercam, tão distintamente quanto conhecemos os diversos misteres dos nossos artífices, poderíamos empregálos igualmente a todos os usos para os quais são próprios, e desse modo nos tornar como que senhores e possuidores da natureza" (DESCARTES, 2008 , p. 60 , os grifos são nossos).

Geografia Ensino \& Pesquisa, v. 15, n.3, p. 7-26, set./dez. 2011

A politica de desenvolvimento sustentável da implementando novas prioridades estratégicas, tais como minimização de custos, flexibilidade operacional e financeira e combinação entre preservação de caixa e busca por rentáveis opções de crescimento" (VALE, 2009c, p. 6).

Sendo assim, o que explica tal empresa demitir mais de 2 mil trabalhadores diretos ${ }^{16}$ e 12 mil terceirizados de um total de 120 mil trabalhadores em todo o mundo, sendo a metade terceirizada ${ }^{17}$, já que o lucro líquido fora de US $\$ 13,2$ bilhões? 0 fazer e 0 falar estão cada vez mais longe um do outro, e isso é uma estratégia discursiva. A herança da Vale em território maranhense, seria esse um legado positivo? Um legado de submoradia, deficiência de saneamento básico e poluição atmosférica. Equilíbrio socioambiental e equilíbrio crematístico, juntos, é pura fantasia nesse modelo de racionalidade, uma vez que a racionalidade nem econômica é, pois não cuida do aprovisionamento material da casa familiar; a racionalidade é crematística, ou seja, estuda a formação dos preços de mercado, para ganhar dinheiro. $O$ valor da Vale é constituído ou convertido em valor de troca como já salientamos (RIBEIRO JUNIOR; SANT'ANA JÚNIOR, 2010).

\section{Considerações finais: A insuficiência política para a Querela Ambiental}

A dimensão política está imbricada, hoje, em vários âmbitos do conhecimento científico. Como não poderia deixar de ser, a questão ambiental, a partir do momento em que necessitou ser analisada, requereu o direcionamento da política para o seu campo. 0 discurso de desenvolvimento, que é essencialmente histórico e dispõe-se em acontecimentos reais e sucessivos (FOUCAULT, 2009), também teve a necessidade de políticas sustentáveis.

Objetivamente, viu-se que a política de desenvolvimento sustentável da Vale traduz-se em mais um vetor de geração de lucro e forma de agregar valor às ações da empresa.

Em princípio, o "operador sustentável", transforma-se, com o decorrer da análise, em um operador in-sustentável. Isso porque opera com a lógica do valor de troca, ou seja, a natureza transmite certo poder de compra. Ressalte-se que, como foi avaliado, a Vale reduz o problema ambiental a um problema tecnológico, bem como professa a sua fé no evangelho da ecoeficiência. Como salientamos, a tecnologia por si só não resolve os problemas de ordem ambiental, haja vista a tecnologia em questão que é produto de um modelo de racionalidade que é cartesiana ${ }^{18}$ (senhora e possuidora da Natureza), mercantil e crematística. 0 evangelho da eco-eficiência, tão bem aludido por Martínez Alier (2007), materializa-se na Vale em suas atividades industriais, em sua linguagem discursiva que substitui Natureza por recursos naturais e na dimensão religiosa do utilitarismo e da eficiência técnica.

Após avaliarmos a questionável sustentabilidade da Vale, vimos que a referida empresa se transforma numa "enzima" que age como "catalisador do desenvolvimento local". Esse jogo de palavras biológico é perfeitamente compatível com a nossa análise, posto que, não podemos olvidar que desenvolvimento também implica em competição. E se implica competição, traz consigo a essência biológica da competição: uma relação desarmônica em que uma das partes sai perdendo, no nosso caso a sociedade civil atingida pela Vale. Nesse ponto, o interesse maior foi centrar a discussão, mesmo que de forma incipiente, na ideia de desenvolvimento. $E$, como foi exposto, desenvolver é, na verdade, des-envolver, ou seja, é retirar a autonomia que cada 
cultura e povo mantêm com seu território. Logo, podemos concluir que a Vale contribuiu verdadeiramente, por exemplo, para o des-envolvimento do Maranhão, pois ao fazê-lo desterritorializou maranhenses, contribuiu para o inchaço populacional de cidades, favelização, submoradia, deficiência de saneamento básico, poluição ambiental e proliferação de conflitos socioambientais no espaço maranhense.

A atuação "enzimática" da Vale no "organismo" maranhense nos direcionou para o questionamento de sua globalidade enquanto agente da sustentabilidade. Observamos que pari passu a sua globalidade tem-se a sua impactabilidade também em nível global. 0 exemplo vem do Canadá, onde existem dois processos judiciais envolvendo a Inco que ainda carece de decisão final. Um caso diz respeito à sanção monetária imposta por alegada contaminação no solo na refinaria de Port Colborne, no qual a empresa vem se defendendo. $O$ outro é referente à sanção monetária por poluição do ar, nas operações de Sudbury (Vale, 2009b). Este exemplo dá uma boa dimensão das boas práticas de sustentabilidade da Vale. Nesse aspecto ressaltamos a importância de uma teoria efetivamente sustentável para que se tenha uma prática sustentável. Apontamos que não existem práticas ditas sustentáveis que pulularam da racionalidade crematística que a Vale segue a risca. É fantasiosa a transparência alegada pela Vale, principalmente se levando em consideração as informações omitidas, e de extraordinária relevância, do sítio do lbase, no que tange aos investimentos para tornar mínimo resíduos e aumentar a eficácia na utilização dos recursos naturais. A liderança das discussões internacionais relacionada ao desenvolvimento sustentável, em que pese seus negócios e operações, não se traduz em discussões internacionais sobre os impactos ambientais que ela causa.

Por isso tudo, é necessário questionar criticamente a "racionalidade valiana". Isso porque essa "submatriz" de racionalidade tem desencadeado sérios conflitos socioambientais no Maranhão. Cabe, agora, ir para além da política de desenvolvimento sustentável que, ao contrário de se configurar como a imposição de limites, institucionaliza, legisla e normatiza 0 des-envolvimento que, como foi abordado, nunca foi e nunca será sustentável.

\section{Referências}

AQUINO, Maria J. S. e SANT'ANA JÚNIOR, Horácio A. Ferro, "Canga", Mangue: conservação ambiental e exploração mineral na Amazônia brasileira. In: FERRETTI, S. F. e RAMALHO, J. R. Amazônia: desenvolvimento, meio ambiente e diversidade sociocultural. São Luís: EDUFMA, 2009.

CMMAD. Comissão Mundial sobre Meio Ambiente e Desenvolvimento. Nosso Futuro Comum. 2.ed. Rio de Janeiro: FGV, 1991.

DESCARTES, René. Discurso do método/Regras para a direção do espirito. São Paulo: Martin Claret, 2008.

Escobar, Arturo. O lugar da natureza e a natureza do lugar: globalização ou pós-desenvolvimento?. In: LANDER, Edgardo (Org.). A Colonialidade do saber: eurocentrismo e ciências sociais. Trad. Júlio César C. B. SILVA. Buenos Aires: CLACSO: 2005. pp.133-168.

FOUCAULT, Michel. A arqueologia do saber. Trad. Luiz Felipe Baeta NEVES. $7^{2}$ ed. Rio de Janeiro: Forense Universitária, 2009.

GODEIRO, Nazareno (org.) Vale do Rio Doce. Nem tudo que reluz é ouro, da privatização à luta pela reestatização. São Paulo: Sundermann, 2007.

Geografia Ensino \& Pesquisa, v. 15, n.3, p. 7-26, set./dez. 2011

Ribeiro Junior, J. A.; Sant'Ana Júnior, H. A.

GRIGATO, R. B; RIBEIRO, L. C. M. Política Ambiental e Responsabilidade Social Empresarial da CVRD. Revista Ágora, Vitória, n.4, 2006. Pp. 1-20. 
HOLANDA, Felipe de. Dinâmica da economia maranhense nos últimos 25 anos. São Luís: IMESC, 2008.

Instituto Maranhense de Estudos Socioeconômicos e Cartográficos. Indicadores de Conjuntura Econômica Maranhense/. V. 1, n. 2 (jul./dez. 2008)._São Luís: IMESC, 2008.

MAGALHÃES, Sônia Barbosa; HERNANDEZ, Francisco Del Moral. Belo Monstro. Contra Corrente, RedeBrasil: Brasília, Novembro de 2009. p.31-32.

MARTÍNEZ ALIER, Juan. O Ecologismo dos Pobres: conflitos ambientais e linguagens de valoração. Trad. Mauricio WALDMAN. São Paulo: Contexto, 2007.

Notícias STEFEM. STEFEM denuncia Vale no MP por emissão de poluentes em São Luís. Sindicato dos Trabalhadores em empresas ferroviárias dos Estados do Maranhão, Pará e Tocantins - Ano 4 - №12 Março/2010.

Organizações Integrantes do I Encontro Internacional dos Atingidos pela Vale. Dossiê dos impactos e violações da Vale no mundo. Disponível em CD. 2010

PORTO-GONÇALVES, Carlos Walter. A globalização da natureza e a natureza da globalização. Rio de Janeiro: Civilização Brasileira, 2006.

RIBEIRO JUNIOR, J. A. S; SANT'ANA JÚNIOR, H. A. Análise crítica do desempenho da Vale em 2009. VII Jornada Maranhense de Sociologia, Universidade Federal do Maranhão, 28 de setembro a 01 de outubro de 2010.

SANT'ANA JÚNIOR, H. A; MUNIZ, L. M. Desenvolvimento sustentável: uma discussão crítica sobre a proposta de busca da sustentabilidade global. In: SANT'ANA JÚNIOR, H. A et alli (org.). Ecos dos conflitos socioambientais: a RESEX de Tauá-Mirim. São Luís: EDUFMA, 2009. p. 255-276.

VALE. Política de Desenvolvimento Sustentável. Disponível em www.vale.com. Conteúdo Institucional acessado em 17 de dezembro de 2009a.

VALE. Relatório de Sustentabilidade 2007. Disponível em www.vale.com. Conteúdo Institucional acessado em 17 de dezembro de 2009b.

VALE. Relatório de Sustentabilidade 2008. Disponível em www.vale.com. Conteúdo Institucional acessado em 17 de dezembro de 2009c.

VESENTINI, J.W. Novas geopolíticas. $4^{\mathrm{a}}$ ed. $1^{\mathrm{a}}$ reimp. São Paulo: Contexto, 2007.

VIAS DE FATO. Entrevista Claudio Bombieri. São Luís: Março de 2010 - Ano 02 Número 06. pp. 5-7.

\section{Correspondência}

José Arnaldo Ribeiro Junior - Rua Dom Pedro I, n²20, Bairro de Fátima, São Luís-Maranhão. CEP: 65030-430

E-mail: ajr_tyler@yahoo.com.br

Recebido em 16 de junho de 2011.

Revisado pelo autor em 05 de outubro de 2011.

Aprovado em 28 de outubro de 2011.

Geografia Ensino \& Pesquisa, v. 15, n.3, p. 7-26, set./dez. 2011

A politica de desenvolvimento sustentável da 